\title{
SECTION 6: KAURI WOOD, SAMPLES A AND B
}

\subsection{INTRODUCTION}

Kauri wood, a sub-fossil wood from New Zealand (which had previously been used in an IAEA exercise, IAEA-C4, in 1990), was considered to be an important sample to include in FIRI because it provided a link to previous exercises, was available in sufficient quantity, and was a "close to background" organic sample. IAEA-C4 had previously been criticized since it was believed that in its milling, some contamination had been introduced, so that a replacement sample would prove useful. The Kauri wood has a very low ${ }^{14} \mathrm{C}$ activity and, as such, is very sensitive to even small amounts of contaminant carbon. Such low-activity samples give a true test for the laboratory procedures since pretreatment and laboratory background definition become critical.

In 1994, a further Kauri wood sample was used in a small intercomparison (Hogg et al. 1995) as a potential replacement for $\mathrm{C} 4$. This new Kauri sample was tested in 6 laboratories and a preliminary range was quoted by the authors.

\subsubsection{Preliminary Testing Results}

From the earlier work on this sample (Hogg et al. 1995) involving 6 laboratories, the authors concluded:

- It was not possible to assign a definitive $\mathrm{pMC}$ value to the sample and the authors suggested a range of $0.12-0.21 \mathrm{pMC}$.

- The results showed some evidence of in-homogeneity (probable causes being incorrect background assessment or inadequate sample pretreatment).

Nonetheless, it was decided that this new Kauri sample should be included in FIRI, and that it should be provided in duplicate, without pretreatment.

\subsection{PRELIMINARY RESULTS}

A total of 83 laboratories returned results within the deadline. Due to some laboratories using more than one preparation or measurement system, this gave a set of over 90 results. It is worth noting the following:

- The basic results for the Kauri samples (A and B) were often given in 2 forms, age and pMC;

- The errors (particularly for age) were asymmetrical;

- There was a substantial number of censored observations (observations reported as "greater than");

- Some results were simply given as "background."

Thus, it is apparent that there is an important variation in how the results are reported.

\subsubsection{Preliminary Analysis}

The preliminary analysis focused on the distribution of results, the identification of any gross outliers (using simple graphical means such as boxplots), and the calculation of preliminary consensus values based on robust statistics (medians and interquartile ranges).

In this section, the 2 independently measured duplicate samples are reported separately and then the combined results are analyzed. Finally, a comparison of the results for AMS, GPC, and LSC laboratories is reported. 


\subsubsection{Sample A}

Ninety-eight age results were quoted, 64 of which were finite, while 5 were simply quoted as background. For pMC, 67 finite results were quoted (not all laboratories quoted both age and pMC, and for the preliminary analysis, no conversion calculations were performed, although this was done later), and 2 laboratories simply quoted the result as background. The results came from 32 AMS, 20 GPC, and 44 LSC systems. Summary information on the results reported is shown in Table 6.1 below.

Table 6.1 Summary of the reporting format for Kauri A

\begin{tabular}{|c|c|c|c|c|c|c|c|}
\hline \multicolumn{4}{|c|}{ a) Age } & \multicolumn{4}{|c|}{ b) $\mathrm{pMC}$} \\
\hline Reporting format & AMS & GPC & LSC & Reporting format & AMS & GPC & LSC \\
\hline$>$ & 9 & 7 & 9 & $<$ & 3 & 2 & 1 \\
\hline Background & 0 & 1 & 4 & Background & 0 & 1 & 1 \\
\hline Finite & 23 & 12 & 29 & Finite & 27 & 14 & 26 \\
\hline
\end{tabular}

\subsubsection{Distribution of Results}

Figure 6.1 shows a boxplot with the censored $(>)$ observations distinguished from the finite (uncensored) results.

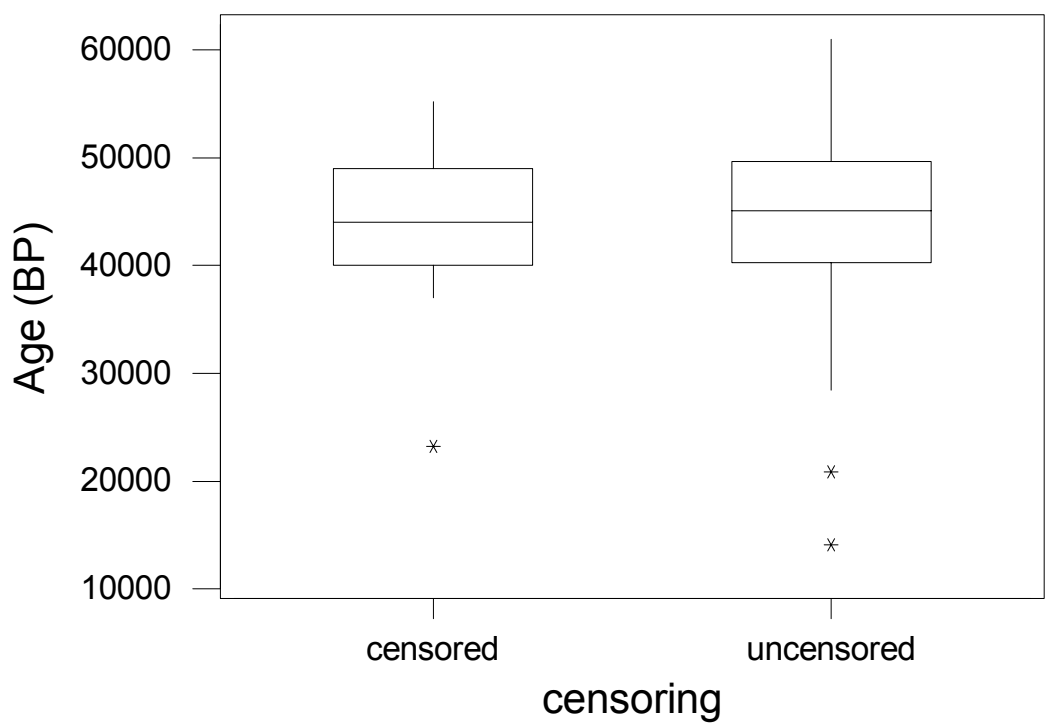

Figure 6.1 Age distribution for Kauri A

There appears to be little difference in location (activity distribution) for the censored and uncensored results. The boxplots also permit a preliminary identification of gross outliers, represented by asterisks in the figure above. Three obvious outliers with ages less than 22,000 BP are apparent.

In pMC, 3 outliers were immediately apparent with values of $7.43,10.62$, and 17.31 . Figure 6.2 shows the boxplot of pMC after their removal. 


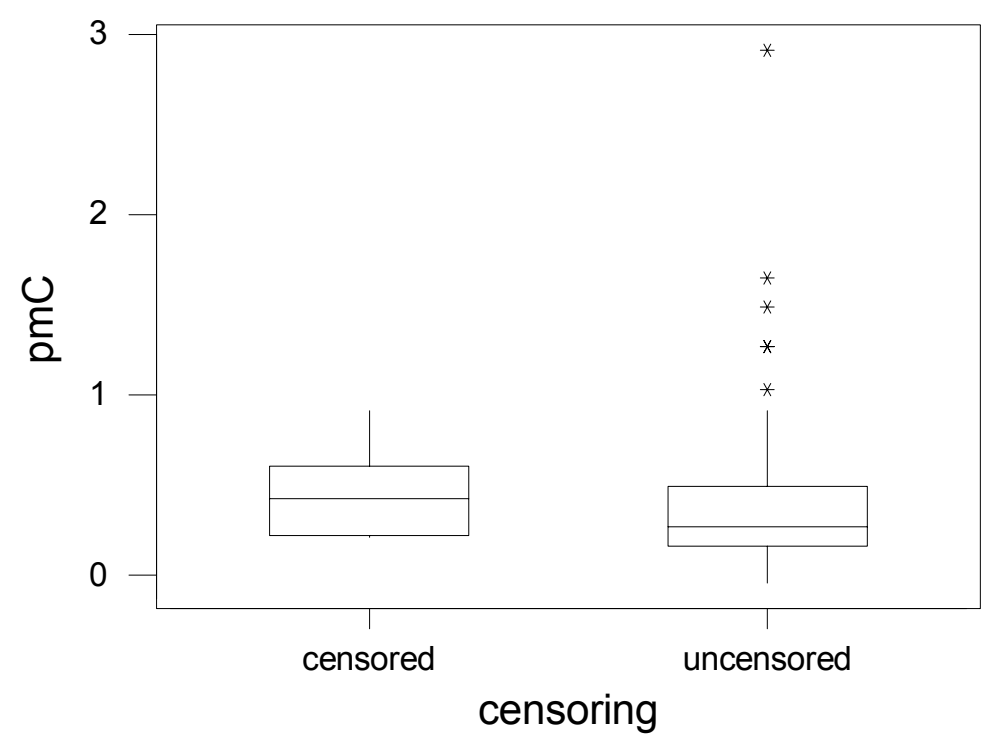

Figure 6.2 pMC distribution for Kauri A (outliers 7.43, 10.62, and 17.31 removed)

\subsubsection{Summary Statistics (Omitting Outliers)}

For finite ages, the overall mean is $44,482 \mathrm{yr}$, the median is $45,200 \mathrm{yr}$, and standard error of the mean (Semean) is $885 \mathrm{yr}$. The results for the 3 laboratory types are shown in Table 6.2 below.

Table 6.2 Summary ages for Kauri A by laboratory type

\begin{tabular}{lllc}
\hline Laboratory type & Mean & Median & Semean \\
\hline AMS & 48,180 & 49,200 & 897 \\
GPC & 46,534 & 46,468 & 2196 \\
LSC & 40,565 & 41,140 & 1270 \\
\hline
\end{tabular}

There are statistically significant differences in the means between LSC and both AMS and GPC laboratories.

For pMC, the overall mean is 0.4181 , the median is 0.2705 , and standard error of the mean is 0.0582 .

Table 6.3 Summary results for pMC for Kauri A by laboratory type

\begin{tabular}{llll}
\hline Laboratory type & Mean & Median & Semean \\
\hline AMS & 0.2741 & 0.2 & 0.0504 \\
GPC & 0.3094 & 0.25 & 0.0636 \\
LSC & 0.653 & 0.45 & 0.135 \\
\hline
\end{tabular}

There is a statistically significant difference in the average pMC between LSC and AMS laboratories.

\subsubsection{Duplicate B}

Ninety-nine age results were returned, 57 of which were finite and 7 simply quoted as background. For pMC, 64 results were finite and 2 were quoted as background. Results were received from 33 AMS, 21 GPC, and 45 LSC systems. 
Table 6.4 Summary of reporting format for Kauri B

\begin{tabular}{|c|c|c|c|c|c|c|c|}
\hline \multicolumn{4}{|c|}{ a) Age } & \multicolumn{4}{|c|}{ b) $\mathrm{pMC}$} \\
\hline Reporting format & AMS & GPC & LSC & Reporting format & AMS & GPC & LSC \\
\hline$>$ & 11 & 10 & 10 & $<$ & 5 & 2 & 2 \\
\hline Background & 0 & 2 & 5 & Background & 0 & 1 & 1 \\
\hline Finite & 22 & 9 & 26 & Finite & 26 & 15 & 23 \\
\hline
\end{tabular}

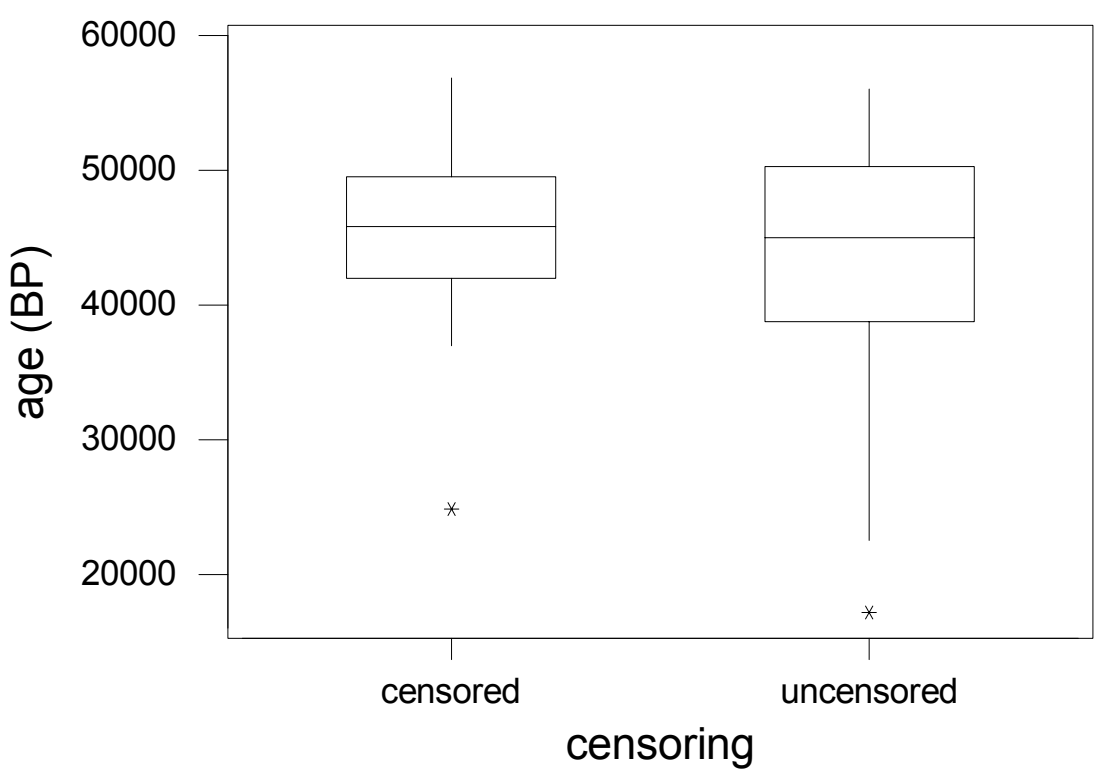

Figure 6.3 Age distribution for Kauri B

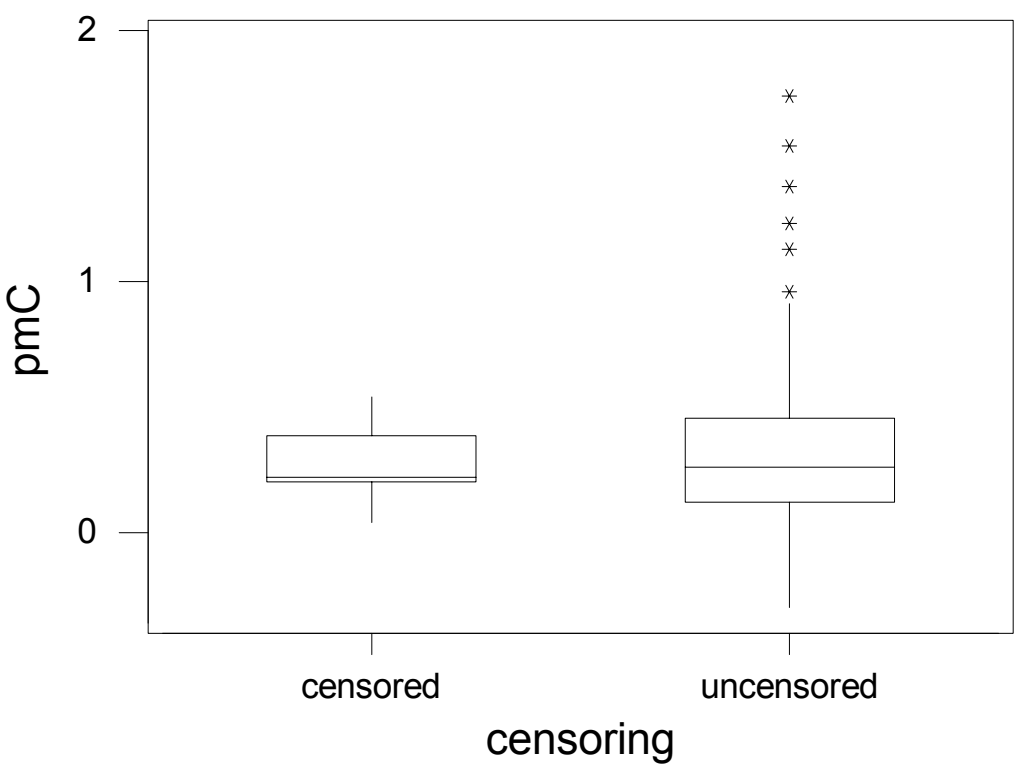

Figure $6.4 \mathrm{pMC}$ distribution for Kauri B (outliers 4.86 and 8.41 removed) 


\subsubsection{Distribution of Results}

Figures 6.3 and 6.4 show the boxplots with the censored and uncensored observations for age and pMC. A preliminary identification of gross outliers indicates 2 outliers with ages less than 22,000 $\mathrm{BP}$ and in pMC, 2 outliers were identified with values of 4.86 and 8.41 .

For finite ages, the overall mean is $43,699 \mathrm{yr}$, the median is $45,000 \mathrm{yr}$, and the standard error of the mean is $1086 \mathrm{yr}$.

Table 6.5 Summary ages for Kauri B (with outliers removed)

\begin{tabular}{llll}
\hline & Mean & Median & Semean \\
\hline AMS & 48,942 & 49,350 & 1034 \\
GPC & 40,832 & 42,231 & 3681 \\
LSC & 40,254 & 41,007 & 1419 \\
\hline
\end{tabular}

Statistically significant differences in age were observed between AMS and both LSC and GPC laboratories.

For pMC, the overall mean is 0.38 , with a median of 0.26 , and a standard error of the mean of 0.05 .

Table 6.6 Summary pMC for Kauri B (with outliers removed)

\begin{tabular}{llll}
\hline & Mean & Median & Semean \\
\hline AMS & 0.2373 & 0.1750 & 0.037 \\
GPC & 0.348 & 0.237 & 0.122 \\
LSC & 0.5888 & 0.44 & 0.096 \\
\hline
\end{tabular}

A statistically significant difference between LSC and AMS results was observed. Again, it is clear that the median tends to be older than the mean. Other extreme observations are also highlighted.

\subsubsection{Combined Results}

Since the samples were duplicates (each being split from a single block of $100 \mathrm{~g}$ ), the results can be combined.

For age, 197 results in total were returned, 120 of which were finite and 12 simply quoted as background. For pMC, there were 125 finite results and 4 quoted as background. Overall, there were 65 AMS, 39 GPC, and 93 LSC measurements.

Table 6.7 Summary of reporting format for Kauri A and B

\begin{tabular}{|c|c|c|c|c|c|c|c|}
\hline \multicolumn{4}{|c|}{ a) Age } & \multicolumn{4}{|c|}{ b) $\mathrm{pMC}$} \\
\hline Reporting format & AMS & GPC & LSC & Reporting format & AMS & GPC & LSC \\
\hline$>$ & 21 & 17 & 19 & $<$ & 9 & 4 & 16 \\
\hline Background & 0 & 3 & 9 & Background & 0 & 2 & 4 \\
\hline Finite & 44 & 19 & 57 & Finite & 52 & 29 & 44 \\
\hline
\end{tabular}

\subsubsection{Distribution of Results}

Figures 6.5 and 6.6 show the boxplots with the censored and uncensored observations marked separately for age and pMC. A preliminary identification shows 2 clear age outliers with ages of 14,090 and $17,180 \mathrm{BP}$. 


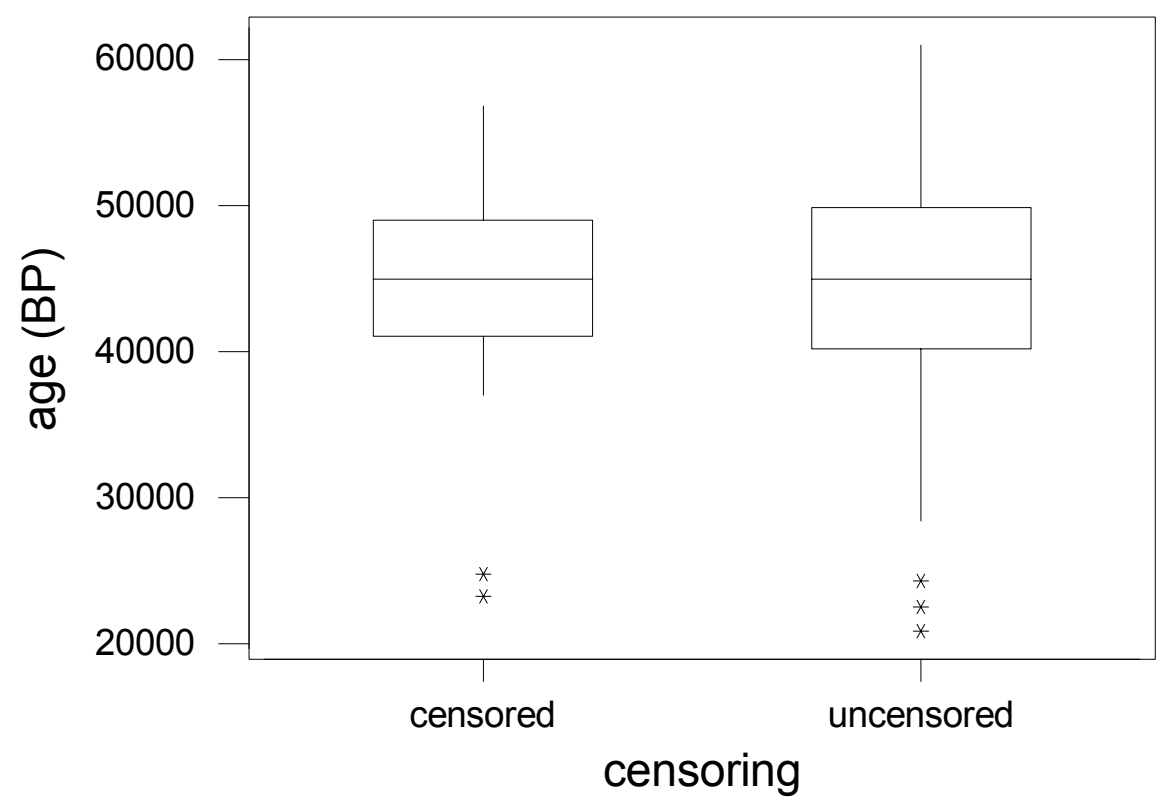

Figure 6.5 Age distribution for Kauri A and B (outliers 14,090 and 17,180 removed)

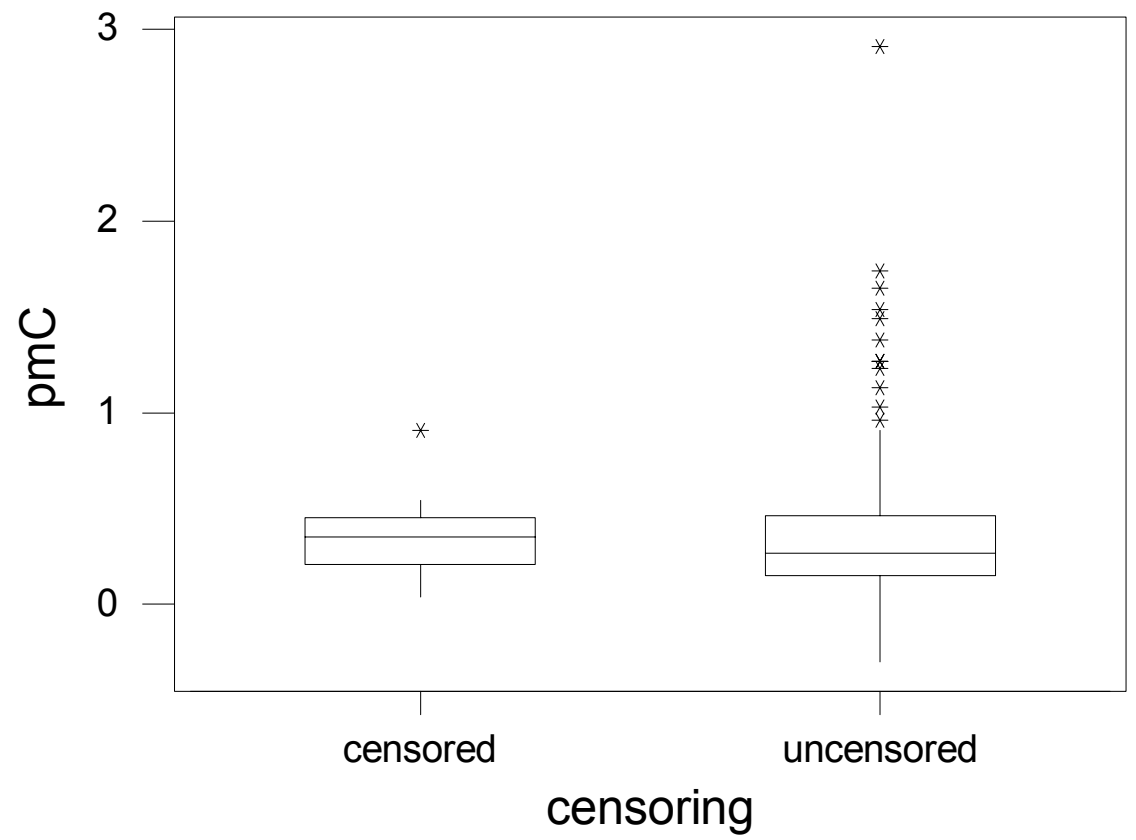

Figure 6.6 pMC distribution for Kauri A and B (outliers 4.86, 8.41, 7.43, 10.62, and 17.31 removed)

For pMC, 5 clear outliers were identified with values of $4.86,8.41,7.43,10.62$, and 17.31.

For finite ages, the overall mean is 44,336 BP, with a median of 45,000 BP, and a standard error of the mean of $660 \mathrm{yr}$. 
Table 6.8a Summary results for Kauri A and B age (yr BP) by laboratory type

\begin{tabular}{lllc}
\hline & Mean & Median & Semean \\
\hline AMS & 48,552 & 49,200 & 677 \\
GPC & 44,617 & 44,043 & 1495 \\
LSC & 40,789 & 41,013 & 996 \\
\hline
\end{tabular}

A statistically significant difference between LSC and AMS results was observed.

Table $6.8 \mathrm{~b}$ Summary results for Kauri A and B (pMC) by laboratory type

\begin{tabular}{llll}
\hline & Mean & Median & Semean \\
\hline AMS & 0.2561 & 0.19 & 0.0313 \\
GPC & 0.3292 & 0.24 & 0.0691 \\
LSC & 0.6225 & 0.445 & 0.0831 \\
\hline
\end{tabular}

The overall mean pMC is 0.40 , with a median of 0.26 , and a standard error of the mean of 0.038 .

A statistically significant difference between mean pMC for LSC and AMS systems and LSC and GPC systems was observed.

\subsection{CONCLUSIONS BASED ON THE PRELIMINARY ANALYSIS}

For all Kauri sample results, a preliminary analysis gives a median $\mathrm{pMC}$ value of 0.24 and interquartile range (IQR) of $0.15-0.44$. The mean is noticeably higher $(0.38)$ since it is non-robust and affected by extreme values. The results are also higher than those quoted by Hogg et al. (1995), but are based on a much wider group of laboratories. This analysis has only excluded the most extreme outliers. However, there is clearly some considerable variation in the results, which may be a function of laboratory background (estimation and material used) and the limits of detection. Interestingly, the analysis also appears to indicate some differences in the distribution of results between laboratory types, with AMS laboratories quoting older ages in general.

\subsection{ANALYSIS OF ACTIVITY, A AND B SEPARATELY}

Analysis for Kauri A and B should, in principle, follow a similar approach to that for Samples C-J, but this must be modified when considering the age of the sample and the issue of finite age reporting. By this we mean that for age, many results were simply quoted as "greater than" or indeed as "background" (described as "censored"). However, the analysis of the pMC results (since the majority of results are given in a finite form) will follow a similar pattern to the analysis for the other samples. Following the exploratory analysis, outliers have been omitted.

First, we investigate the association, if any, between whether a measurement is censored and other laboratory factors.

\subsubsection{Association Between Censoring and Laboratory Factors}

\subsubsection{Kauri $A$}

Table 6.9a Reporting status by laboratory type

\begin{tabular}{lcccc}
\hline & AMS & GPC & LSC & All \\
\hline Censored & 3 & 3 & 3 & $\mathbf{9}$ \\
Uncensored & 28 & 14 & 28 & $\mathbf{7 0}$ \\
All & 31 & 17 & 31 & $\mathbf{7 9}$ \\
\hline
\end{tabular}


No evidence of an association is found; thus, one laboratory type is no more likely to report censored results than any other.

Table $6.9 \mathrm{~b}$ Reporting status by modern standard used

\begin{tabular}{lllllclc}
\hline & ASUC & Benz & NBS1 & NBS12 & NBS2 & Other & All \\
\hline Censored & 1 & 0 & 2 & 1 & 3 & 2 & $\mathbf{9}$ \\
Uncensored & 5 & 4 & 21 & 5 & 25 & 6 & $\mathbf{6 6}$ \\
All & 6 & 4 & 23 & 6 & 28 & 8 & $\mathbf{7 5}$ \\
\hline
\end{tabular}

Although not able to complete a formal statistical test due to the small numbers in some cells, there is no strong evidence of a statistically significant association between the reporting status and the modern standard.

Table 6.9c Reporting status by background material used

\begin{tabular}{lcclllllc}
\hline & Anth & Benz & Calc & Charc & Coal & Graph & Marble & Other \\
\hline Censored & 0 & 2 & 0 & 1 & 0 & 0 & 2 & 3 \\
Uncensored & 16 & 13 & 1 & 1 & 8 & 8 & 5 & 11 \\
All & 16 & 15 & 1 & 2 & 8 & 8 & 7 & 14 \\
\hline
\end{tabular}

Although not able to complete a formal test, there is no strong evidence of a statistically significant association between the reporting status and the background material.

\subsubsection{Kauri $B$}

Table 6.10a Reporting status by laboratory type

\begin{tabular}{lcccl}
\hline & AMS & GPC & LSC & All \\
\hline Censored & 5 & 3 & 4 & $\mathbf{1 2}$ \\
Uncensored & 27 & 14 & 22 & $\mathbf{6 3}$ \\
All & 32 & 17 & 26 & $\mathbf{7 5}$ \\
\hline
\end{tabular}

There is no statistically significant association between the laboratory type and the censoring mechanism.

Table $6.10 \mathrm{~b}$ Reporting status by modern standard

\begin{tabular}{lllclcll}
\hline & ASUC & Benz & NBS1 & NBS12 & NBS2 & Other & All \\
\hline Censored & 1 & 0 & 4 & 1 & 4 & 2 & $\mathbf{1 2}$ \\
Uncensored & 5 & 2 & 18 & 6 & 23 & 4 & $\mathbf{5 8}$ \\
All & 6 & 2 & 22 & 7 & 27 & 6 & $\mathbf{7 0}$ \\
\hline
\end{tabular}

There is no statistically significant association between the modern standard and the censoring mechanism.

Table 6.10c Reporting status by background

\begin{tabular}{lcclllllc}
\hline & Anth & Benz & Calc & Charc & Coal & Graph & Marble & Other \\
\hline Censored & 0 & 2 & 0 & 1 & 1 & 0 & 2 & 5 \\
Uncensored & 15 & 8 & 1 & 1 & 8 & 8 & 4 & 10 \\
All & 15 & 10 & 1 & 2 & 9 & 8 & 6 & 15 \\
\hline
\end{tabular}




\subsubsection{Conclusions}

In all cases, no statistically significant association was found; thus, there is no evidence that one type of laboratory, modern standard material, or background material, is linked to whether the result is censored.

\subsection{ANALYSIS OF ACTIVITY: SOURCES OF VARIATION}

In this section, we now consider the effect of laboratory type, modern standard, and background material on pMC (for the purposes of this analysis, we ignore the 6 censored values and treat them as uncensored). Figure 6.7 shows the distribution of results by the 3 factors. Some variation in the results is apparent.

\subsubsection{Kauri A}

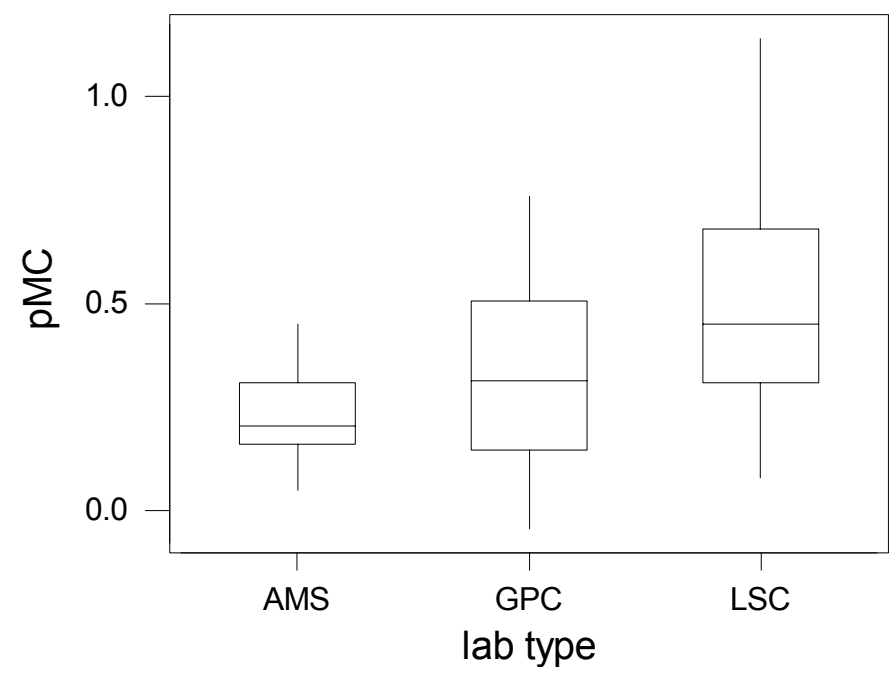

Figure 6.7a Distribution by laboratory type

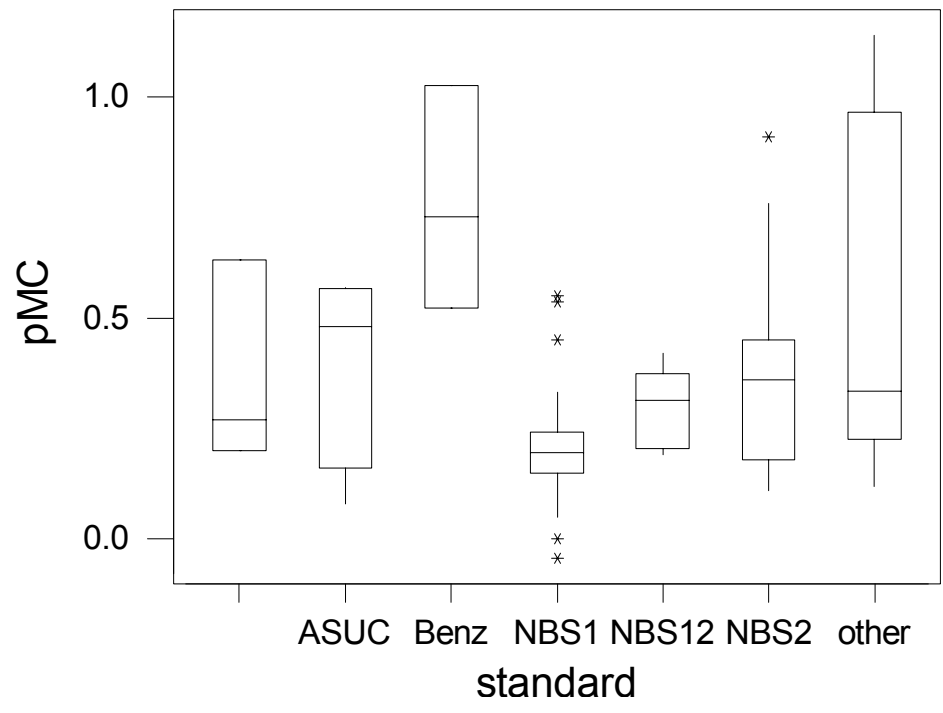

Figure $6.7 \mathrm{~b}$ Distribution by modern standard 


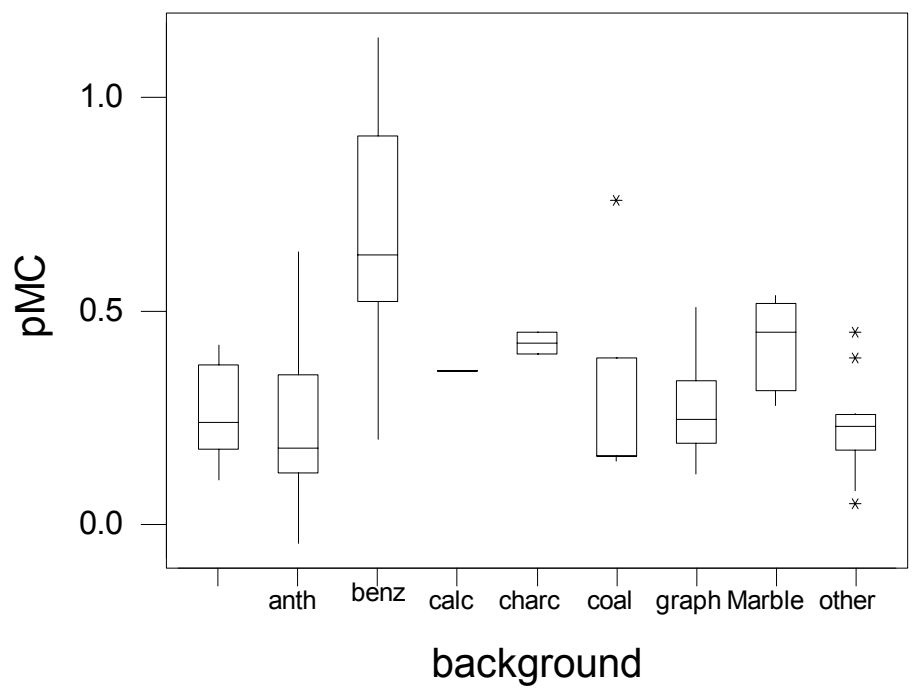

Figure $6.7 \mathrm{c}$ Distribution by background material

\subsubsection{Formal Analysis}

The formal analysis for each factor takes into account the hypothesis that there is no difference in the mean pMC due to the different levels of the laboratory factors. The results are shown in Table 6.11.

Table 6.11a Effect of laboratory type

\begin{tabular}{|c|c|c|c|c|}
\hline Source & $\mathrm{DF}$ & SS & MS & F \\
\hline type & 2 & 0.9316 & 0.4658 & 10.52 \\
\hline Error & 64 & 2.8328 & 0.0443 & \\
\hline \multirow[t]{2}{*}{ Total } & 66 & 3.7645 & & \\
\hline & & & & $\begin{array}{l}\text { Individual 95\% CIs For Mean } \\
\text { Based on Pooled StDev }\end{array}$ \\
\hline Level & $\mathrm{N}$ & Mean & StDev & --------+----------++----------+---------- \\
\hline AMS & 30 & 0.2358 & 0.0999 & $(------\star-----)$ \\
\hline GPC & 16 & 0.3301 & 0.2287 & $(--------\star-------)$ \\
\hline LSC & 21 & 0.5098 & 0.2966 & $(------\star-------)$ \\
\hline Pooled & StDev $=$ & 0.2104 & & 0.36 \\
\hline
\end{tabular}

Table $6.11 \mathrm{~b}$ Effect of modern standard

\begin{tabular}{|c|c|c|c|c|}
\hline Source & $\mathrm{DF}$ & SS & MS & $\mathrm{F}$ \\
\hline standard & 5 & 1.0910 & 0.2182 & 0.001 \\
\hline Error & 58 & 2.5637 & 0.0442 & \\
\hline \multirow[t]{2}{*}{ Total } & 63 & 3.6547 & & \\
\hline & & & & $\begin{array}{l}\text { Individual 95\% CIs For Mean } \\
\text { Based on Pooled StDev }\end{array}$ \\
\hline Level & $\mathrm{N}$ & Mean & StDev & ------+----------+----------+----------+- \\
\hline ASUC & 4 & 0.4025 & 0.2287 & $(-------\star--------)$ \\
\hline Benz & 3 & 0.7597 & 0.2538 & $(--------\star---------)$ \\
\hline NBS1 & 22 & 0.2163 & 0.1478 & $(---\star--)$ \\
\hline NBS 12 & 6 & 0.3017 & 0.0906 & $(------\star------)$ \\
\hline NBS 2 & 23 & 0.3653 & 0.2070 & $(---\star--)$ \\
\hline other & 6 & 0.5167 & 0.4086 & $(------\star------)$ \\
\hline Pooled St & $\mathrm{ev}=$ & 0.2102 & & 0.75 \\
\hline
\end{tabular}


Table 6.11c Effect of background material

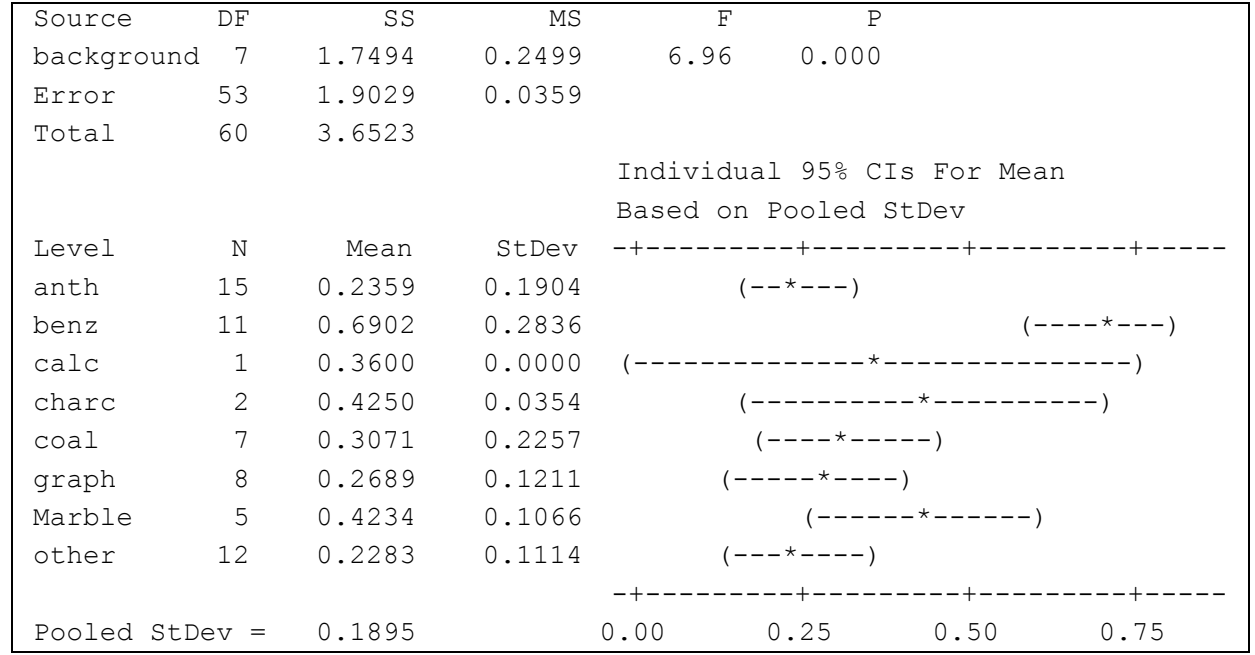

\subsubsection{Conclusions}

A significant laboratory type effect is observed, with AMS laboratories having lower mean quoted pMC. Similarly, a significant modern standard effect is observed, with NBS1 giving the lowest mean pMC. There is also a statistically significant effect of the background material with apparent differences between laboratory results based on anthracite or benzene as the background material.

In all cases for Kauri A, laboratory type (LSC laboratories have, on average, higher pMC than AMS or GPC), modern standard, and background material were all found to be statistically significant.

\subsubsection{Kauri B}

The same analysis is repeated for Kauri B and results presented in the same format. Figure 6.8 shows the considerable variation in the distribution of results over the factor levels.

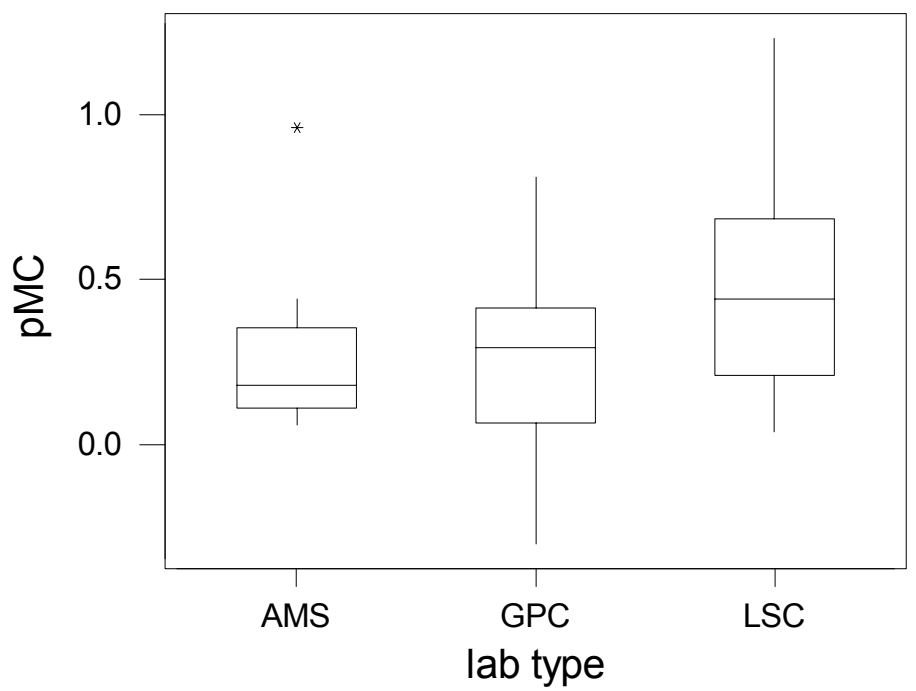

Figure 6.8a Distribution by laboratory type 


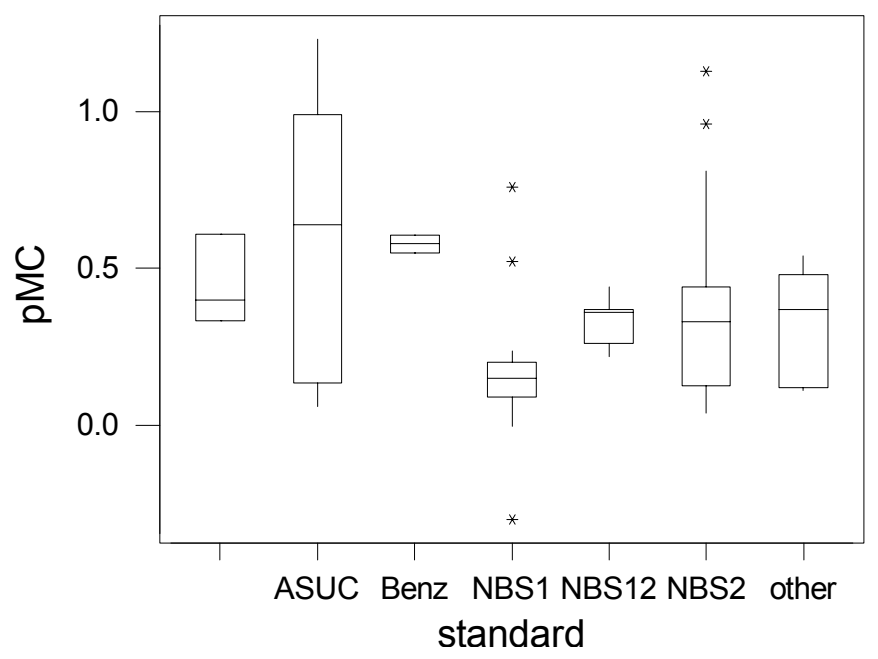

Figure $6.8 \mathrm{~b}$ Distribution by modern standard

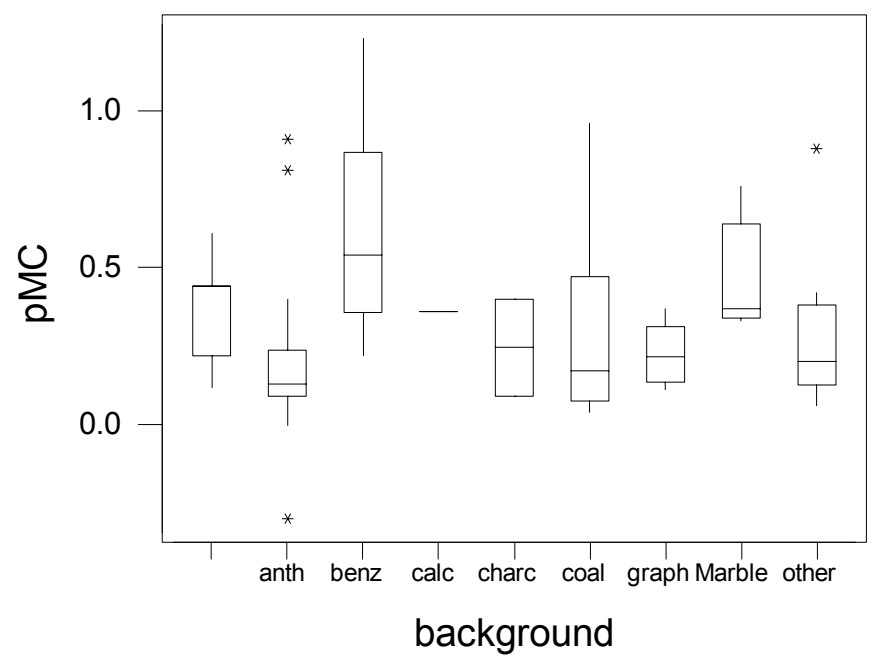

Figure $6.8 \mathrm{c}$ Distribution by background material

\subsubsection{Formal Analysis}

Table 6.12 shows the results of the formal analysis.

Table 6.12a Effect of laboratory type

\begin{tabular}{|c|c|c|c|c|}
\hline Source & $\mathrm{DF}$ & SS & MS & F \\
\hline Type & 2 & 0.9957 & 0.4978 & 0.001 \\
\hline Error & 66 & 4.1679 & 0.0631 & \\
\hline \multirow[t]{2}{*}{ Total } & 68 & 5.1636 & & \\
\hline & & & & $\begin{array}{l}\text { Individual 95\% CIs For Mean } \\
\text { Based on Pooled StDev }\end{array}$ \\
\hline Level & $\mathrm{N}$ & Mean & StDev & 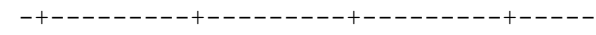 \\
\hline AMS & 32 & 0.2344 & 0.1744 & $\left(-----^{\star}-----\right)$ \\
\hline GPC & 16 & 0.2623 & 0.2681 & $(-------\star--------)$ \\
\hline LSC & 21 & 0.5037 & 0.3276 & $(------\star------)$ \\
\hline Pooled & $\mathrm{ev}=$ & 0.2513 & & 0.30 \\
\hline
\end{tabular}


Table $6.12 \mathrm{~b}$ Effect of modern standard

\begin{tabular}{|c|c|c|c|c|}
\hline Source & $\mathrm{DF}$ & SS & MS & F \\
\hline standard & 5 & 1.1579 & 0.2316 & 0.007 \\
\hline Error & 60 & 3.9150 & 0.0652 & \\
\hline \multirow{2}{*}{ Total } & 65 & 5.0729 & & \\
\hline & & & & $\begin{array}{l}\text { Individual 95\% CIs For Mean } \\
\text { Based on Pooled StDev }\end{array}$ \\
\hline Level & $\mathrm{N}$ & Mean & StDev & --------++---------+------- \\
\hline ASUC & 6 & 0.6067 & 0.4683 & $(-------*--------)$ \\
\hline Benz & 2 & 0.5780 & 0.0396 & $(-------------\star--------------)$ \\
\hline NBS1 & 21 & 0.1646 & 0.1974 & $(----\star---)$ \\
\hline NBS12 & 7 & 0.3357 & 0.0741 & $(------*-------)$ \\
\hline NBS2 & 25 & 0.3504 & 0.2787 & $(---\star---)$ \\
\hline other & 5 & 0.3140 & 0.1877 & $(---------\star--------)$ \\
\hline Pooled St & $\mathrm{ev}=$ & 0.2554 & & 0.50 \\
\hline
\end{tabular}

Table 6.12c Effect of background material

\begin{tabular}{|c|c|c|c|c|}
\hline Source & $\mathrm{DF}$ & SS & MS & $\mathrm{F}$ \\
\hline background & 7 & 1.1787 & 0.1684 & 2.39 \\
\hline Error & 54 & 3.8000 & 0.0704 & \\
\hline \multirow[t]{2}{*}{ Total } & 61 & 4.9787 & & \\
\hline & & & & $\begin{array}{l}\text { Individual 95\% CIs For Mean } \\
\text { Based on Pooled StDev }\end{array}$ \\
\hline Level & $\mathrm{N}$ & Mean & StDev & ------+----------+---------+---------+ \\
\hline anth & 15 & 0.2123 & 0.3019 & $(---\star----)$ \\
\hline benz & 9 & 0.6099 & 0.3459 & $(-----\star-----)$ \\
\hline calc & 1 & 0.3600 & 0.0000 & $(-----------------\star-----------------)$ \\
\hline charc & 2 & 0.2450 & 0.2192 & $(-----------\star-------------)$ \\
\hline coal & 9 & 0.2822 & 0.3064 & $(-----\star-----)$ \\
\hline graph & 8 & 0.2226 & 0.0967 & $(-----\star------)$ \\
\hline Marble & 5 & 0.4662 & 0.1807 & $(-------*------)$ \\
\hline other & 13 & 0.2638 & 0.2183 & $(----\star----)$ \\
\hline Pooled StDe & $\mathrm{ev}=$ & 0.2653 & & 0.60 \\
\hline
\end{tabular}

\subsubsection{Conclusions}

In all cases for Sample B, we have evidence of a statistically significant effect due to laboratory type, modern standard, and background material used. Again, there are apparent differences:

- ANU sucrose results give the highest average pMC;

- There is a difference in the average pMC for anthracite and benzene;

- LSC laboratories quote, on average, higher pMC values.

\subsection{ANALYSIS OF AGE, KAURI A}

We now use the techniques developed in the reliability analysis (see Appendix 3) to explore the age distribution, which, therefore, means that we must utilize both censored and uncensored values. A censored datum is one for which the result is expressed as "> age" BP.

In addition, given the censored nature of the data, non-parametric methods of estimation, used commonly in survival or reliability analyses (in particular, the Kaplan-Meier survival estimator), 
have been used to estimate the "mean" activity of the sample. Reliability plots display the "survival" probabilities versus time, which in this context, is the probability that the sample is greater than age $t$. Each point on the plot represents the proportion of results greater than age $t$ and the nonparametric reliability curve is shown graphically as a step function. In addition, common measures of the center and spread of the distribution of age are estimated. It should be noted that the mean is very sensitive to large ages, while the median, Q1 (25th percentile), Q3 (75th percentile), and interquartile range (IQR) are resistant, so they are quoted in preference.

The outlier definitions used are identical to those used in the pMC analysis.

\subsubsection{Kauri A}

There were 25 censored and 58 uncensored ages. Table 6.13 shows the mean and median age (estimated taking the censoring into account), the quartiles, the interquartile range, and a $95 \%$ confidence interval (CI) for the true mean age.

Table 6.13 Age of Kauri A

\begin{tabular}{llllllll}
\hline & & & & & & \multicolumn{2}{c}{$95.0 \%$ normal CI } \\
\cline { 7 - 8 } Mean & Median & Q1 & Q3 & IQR & Standard error & Lower & Upper \\
\hline 47,007 & 47,935 & 43,900 & 51,530 & 7630 & 808 & 45,423 & 48,590 \\
\hline
\end{tabular}

The mean age is estimated at $47,006 \mathrm{BP}$, with a $95 \%$ CI of $45,423-48,590 \mathrm{BP}$. The median is approximately $1000 \mathrm{yr}$ older than the mean age, suggesting a tail of younger results. The $95 \% \mathrm{CI}$ spans almost $4000 \mathrm{yr}$, indicating the substantial variation in the reported results.

\subsubsection{Sources of Variation}

If we now consider a similar analysis for each of the factors (laboratory type, modern standard, and background material), we can explore the differences in the age distribution of the results that also account for censoring.

For LSC laboratories, there were 26 values, 8 of which were censored; for GPC, there were 17 results, 7 of which were censored values; while for AMS, there were 32 results, 10 of which were censored.

Table 6.14 Age estimation by laboratory type

\begin{tabular}{lllllllll}
\hline & & & & & & & \multicolumn{2}{c}{$95.0 \%$ normal CI } \\
\cline { 7 - 9 } & Mean & Median & Q1 & Q3 & IQR & Standard error & Lower & Upper \\
\hline LSC & 44,155 & 44,024 & 40,190 & 47,600 & 7410 & 1641 & 40,939 & 47,372 \\
GPC & 47,507 & 47,935 & 42,440 & 52,240 & 9800 & 1477 & 44,610 & 50,403 \\
AMS & 49,408 & 50,200 & 47,490 & 51,530 & 4040 & 569 & 48,293 & 50,524 \\
\hline
\end{tabular}

It is clear from Table 6.14 that the AMS laboratories report a significantly older mean age for this sample (median $=50,200 \mathrm{yr} \mathrm{BP}$ ) than either LSC or GPC laboratories.

\subsubsection{Comparison of Age Distributions}

A formal test comparing the age distribution can be carried out and has a p-value $<0.05$, showing quite clearly that there is a significant difference in the age distribution for the 3 laboratory types. Figure 6.9 shows the cumulative age distribution for the 3 laboratory types. This shows that the GPC 
and AMS curves lie clearly above that for LSC. GPC and AMS laboratories are typically measuring and quoting older ages for this sample.

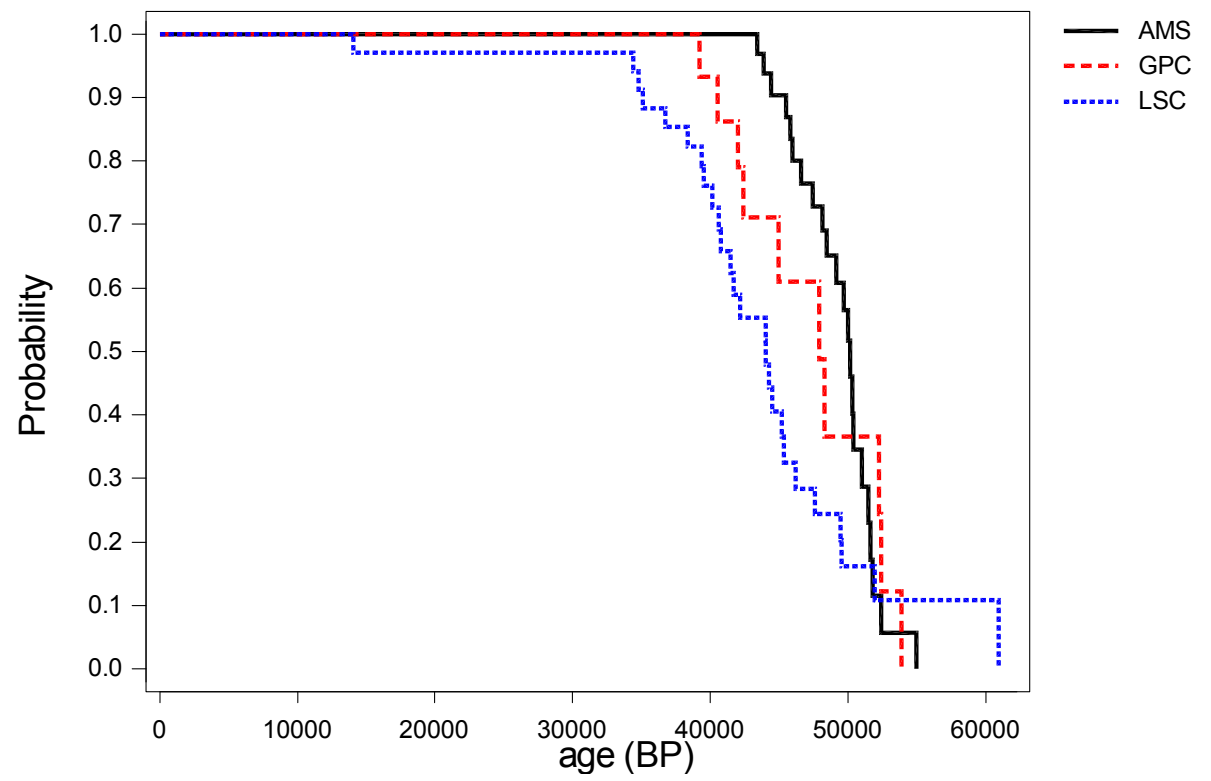

Figure 6.9 Cumulative age distribution by laboratory type

\subsubsection{By Standard Material}

The analysis used previously for the modern standard material is used again and shows a significant difference in the age distribution. Table 6.15 and Figure 6.10 show the age distributions.

Table 6.15 Age estimation by modern standard ${ }^{a}$

\begin{tabular}{lllllllll}
\hline & & & & & & & \multicolumn{2}{c}{$95.0 \%$ normal CI } \\
\cline { 7 - 9 } & Mean & Median & Q1 & Q3 & IQR & Standard error & Lower & Upper \\
\hline Other & 44,800 & 46,610 & 45,000 & 47,935 & 2935 & 2258 & 40,374 & 49,225 \\
NBS2 & 45,995 & 45,398 & 44,024 & 51,971 & 7947 & 1639 & 42,782 & 49,208 \\
NBS12 & 48,233 & 50,300 & 45,500 & 50,300 & 4800 & 1436 & 45,417 & 51,049 \\
NBS1 & 49,399 & 50,200 & 48,305 & 51,800 & 3495 & 731 & 47,966 & 50,832 \\
Benz & 40,585 & 39,556 & 36,780 & 42,211 & 5431 & 2574 & 35,539 & 45,631 \\
Sucrose & 40,425 & $*$ & $*$ & $*$ & $*$ & 1374 & 37,730 & 43,119 \\
\hline
\end{tabular}

a $*$ indicates that there were insufficient data to complete the calculation

\subsubsection{Comparison of Survival Curves}

The summary statistics of the age for each standard type are shown in the following.

The formal test of comparability of the cumulative age distribution results in $p$-values $<0.05$, so we can conclude that there is a statistically significant difference in the age distributions for the different modern standards. Figure 6.10 shows that the benzene curve is lower than all others and suggests that the NBS1 curve is the highest. This would suggest that laboratories using benzene as 
their modern standard are quoting younger ages than laboratories using other modern standard materials.

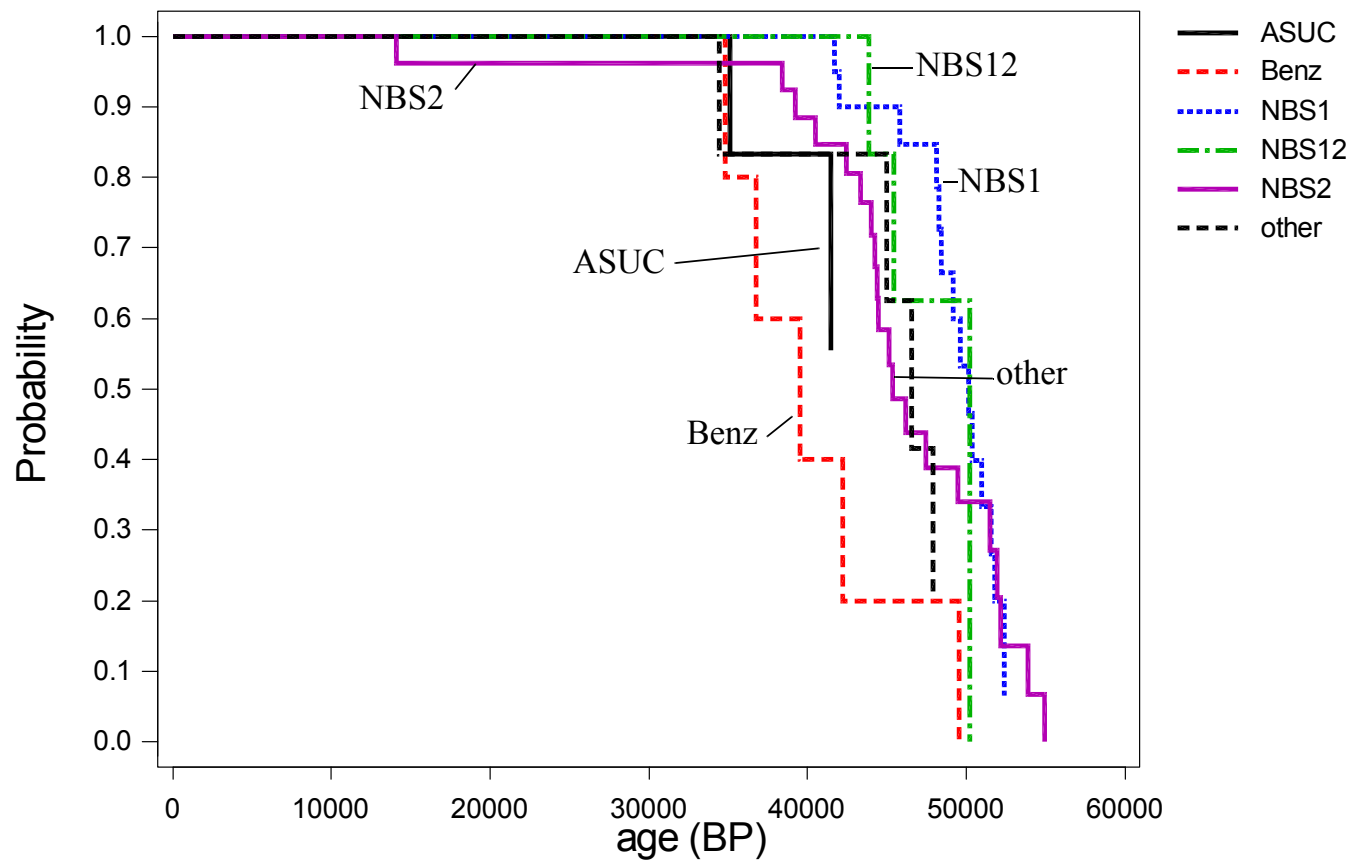

Figure 6.10 Cumulative age distribution by modern standard

\subsubsection{Age Distribution by Background Material}

Table 6.16 and Figure 6.11 repeat a similar analysis, but take into account the background material used.

Table 6.16 Age estimation by background material ${ }^{\mathrm{a}}$

\begin{tabular}{lllllllll}
\hline & & & & & & & \multicolumn{2}{c}{$95.0 \%$ normal CI } \\
\cline { 8 - 10 } & Mean & Median & Q1 & Q3 & IQR & Standard error & Lower & Upper \\
\hline Other & 47,051 & 48,305 & 44,400 & 50,380 & 5980 & 1260 & 44,581 & 49,522 \\
Marble & 41,988 & $*$ & - & - & - & - & $*$ & - \\
Graphite & 47,748 & 47,490 & 45,500 & 50,200 & 4700 & 1005 & 45,777 & 49,720 \\
Coal & 48,014 & 51,530 & 44,480 & 51,800 & 7320 & 1936 & 44,219 & 51,809 \\
Charc & 43,390 & $*$ & - & - & - & $*$ & $*$ & - \\
Anthracite & 48,203 & 52,240 & 45,818 & 53,900 & 8082 & 2574 & 43,156 & 53,249 \\
\hline
\end{tabular}

a $*$ indicates that there were insufficient data to complete the calculation

The formal test again showed a significant difference in the age distribution between the different background materials (as evidenced in Figure 6.11). The results for laboratories using benzene as a background material lie below the curves for other background materials, so the reported ages tend to be younger for those laboratories using benzene as a background material (LSC laboratories) and this is confirmed in Table 6.16. 


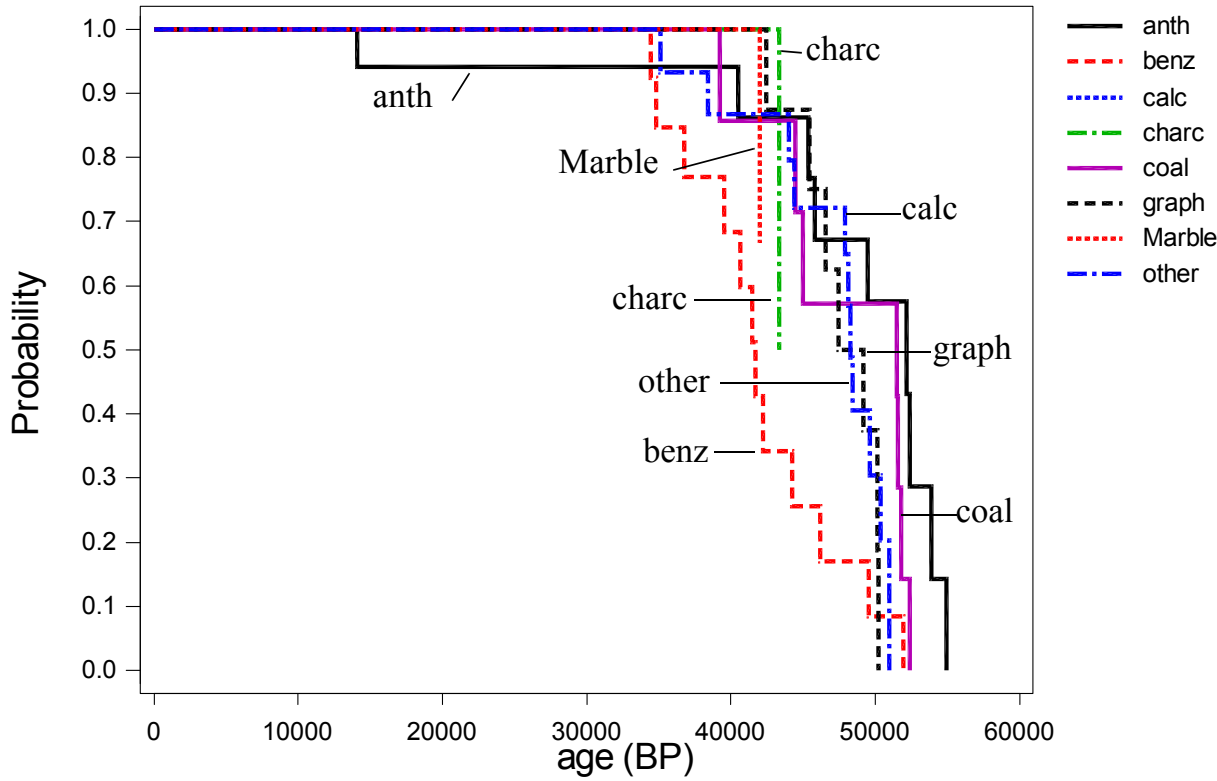

Figure 6.11 Cumulative age distribution by background material

\subsection{ANALYSIS OF AGE, KAURI B}

For Kauri B, a total of 83 measurements were reported, 51 of which were uncensored. The summary of the age distribution is given in the table below.

Table 6.17 Age estimation

\begin{tabular}{llllllll}
\hline & & & & & & \multicolumn{2}{c}{$95.0 \%$ normal CI } \\
\cline { 7 - 8 } Mean & Median & Q1 & Q3 & IQR & Standard error & Lower & Upper \\
\hline 48,210 & 49,815 & 44,043 & 53,393 & 9350 & 730 & 46,779 & 49,641 \\
\hline
\end{tabular}

The mean age is $48,210 \mathrm{BP}$, with the median age being approximately $1000 \mathrm{yr}$ older, again suggesting that the distribution of ages has a long left tail (younger results). The IQR of just over $9300 \mathrm{yr}$ again shows the considerable variation in the results reported.

\subsubsection{Analysis by Laboratory Type}

The formal test of equal cumulative distributions shows a significant difference in age for the different laboratory types (as shown in Table 6.18 and Figure 6.12). For LSC, 10 of 32 measurements were censored, GPC had 10 censored from 17 measurements, and AMS had 12 censored from 34 measurements. Again, we see in the figure that the LSC distribution lies clearly below the GPC and AMS distributions.

Table 6.18 Age distribution for laboratory type

\begin{tabular}{lllllrrrr}
\hline & & & & & & & \multicolumn{2}{c}{$95.0 \%$ normal CI } \\
\cline { 8 - 9 } & Mean & Median & Q1 & Q3 & IQR & Standard error & Lower & Upper \\
\hline LSC & 44,423 & 44,900 & 39,200 & 49,900 & 10,700 & 999 & 42,643 & 46,382 \\
AMS & 50,612 & 51,000 & 46,660 & 54,500 & 7840 & 878 & 48,890 & 52,333 \\
GPC & 53,140 & 53,140 & 44,043 & 53,393 & 9350 & 1661 & 45,681 & 53,393 \\
\hline
\end{tabular}




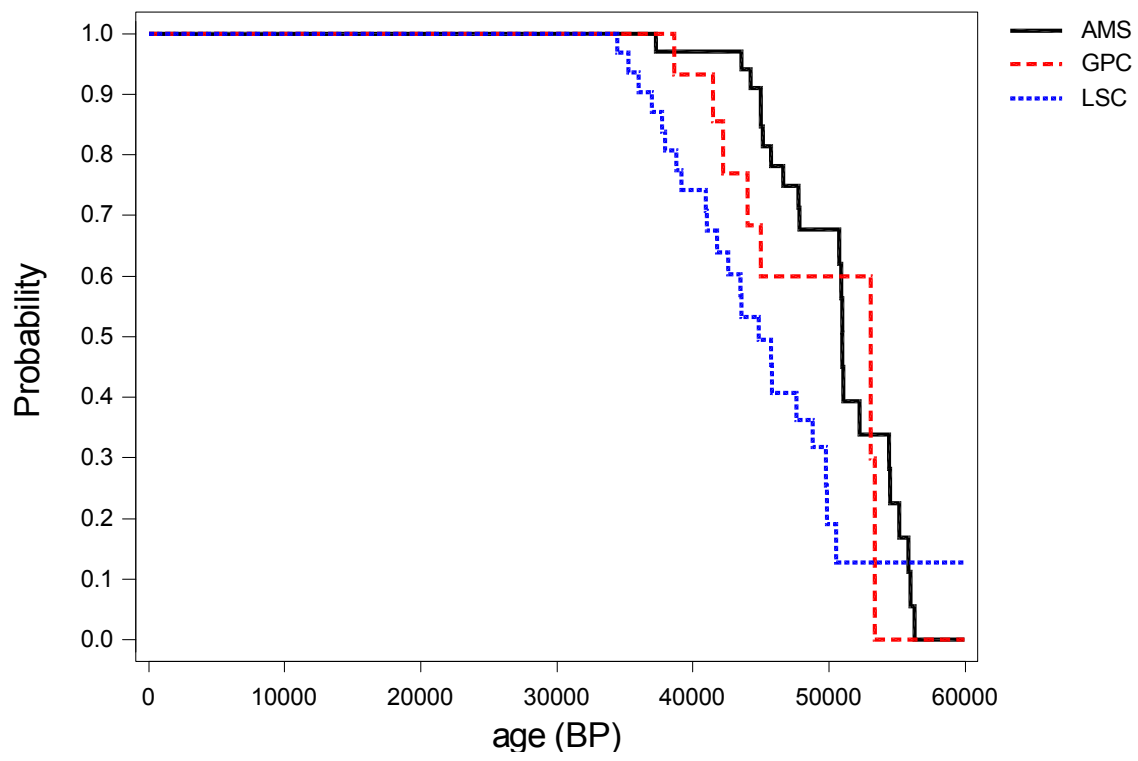

Figure 6.12 Cumulative age distribution by laboratory type

\subsubsection{Age Distribution by Modern Standard}

Figure 6.13 and Table 6.19 show the age distributions for the laboratories using different modern standards. The formal statistical test shows a significant difference in the age distribution, with those laboratories using benzene as the modern standard quoting results that are significantly younger on average.

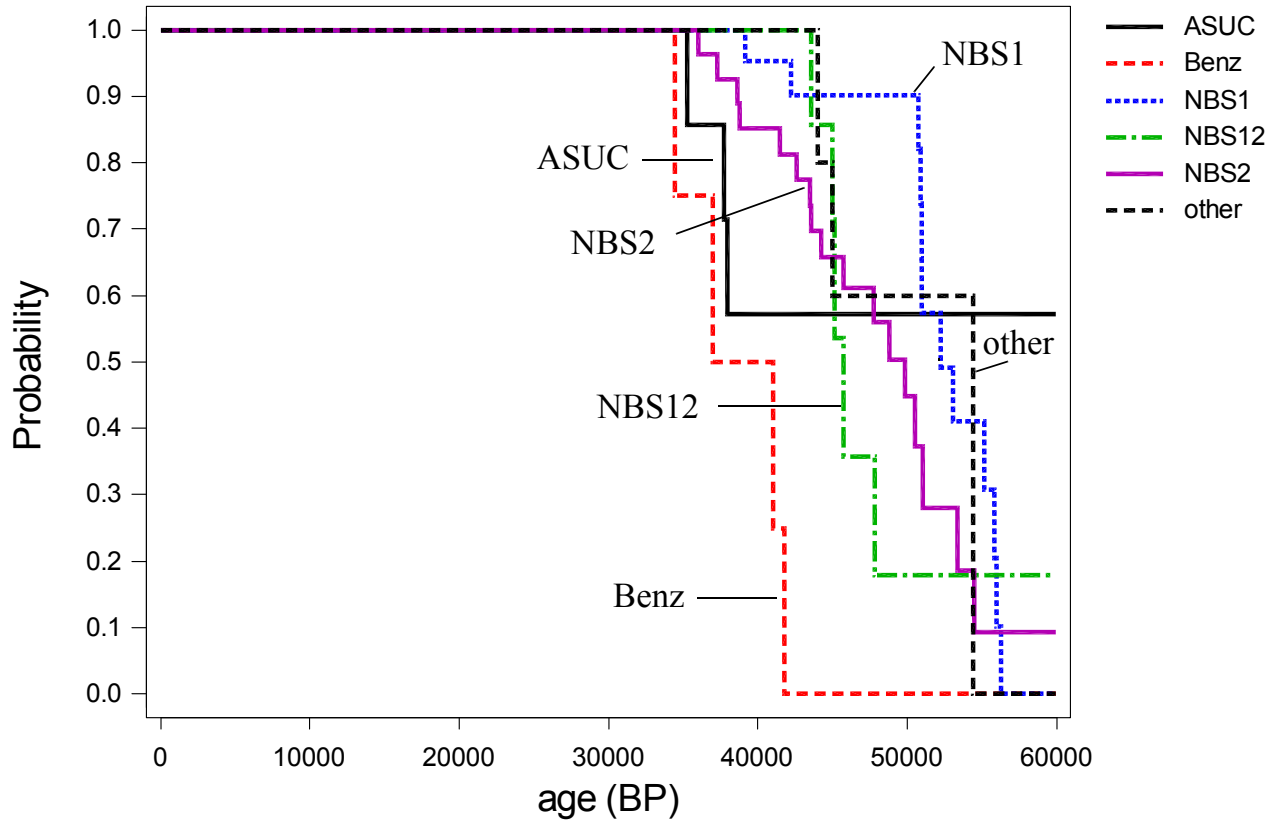

Figure 6.13 Cumulative age distribution by modern standard 
Table 6.19 Age estimation for modern standard type ${ }^{\mathrm{a}}$

\begin{tabular}{lllllllll}
\hline & & & & & & & \multicolumn{2}{c}{$95.0 \%$ normal CI } \\
\cline { 7 - 9 } & Mean & Median & Q1 & Q3 & IQR & Standard error & Lower & Upper \\
\hline Other & 50,492 & 54,473 & 45,000 & 54,473 & 9473 & 2675 & 45,248 & 55,736 \\
NBS2 & 47,766 & 49,900 & 43,540 & 53,393 & 9853 & 1199 & 45,415 & 50,116 \\
NBS12 & 46,014 & 45,800 & 45,000 & 47,900 & 2900 & 686 & 44,668 & 47,360 \\
NBS1 & 52,250 & 52,300 & 50,900 & 55,900 & 5000 & 1092 & 50,109 & 54,390 \\
Benz & 38,549 & 37,000 & 34,420 & 41,013 & 6593 & 1728 & 35,161 & 41,937 \\
Sucrose & 37,584 & $*$ & - & - & $*$ & 431 & 36,739 & 38,429 \\
\hline
\end{tabular}

a $*$ indicates that there were insufficient data to complete the calculation

\subsubsection{Effect of Background Material}

The results (Table 6.20 and Figure 6.14) again show a clear difference in the age distributions due to the background material used. The formal test shows this result is statistically significant, with laboratories using benzene and marble as their background material quoting younger ages.

Table 6.20 Age estimation by background material ${ }^{\mathrm{a}}$

\begin{tabular}{lllllrlll}
\hline & & & & & & & \multicolumn{2}{c}{$95.0 \%$ normal CI } \\
\cline { 7 - 9 } & Mean & Median & Q1 & Q3 & \multicolumn{1}{c}{ IQR } & Standard error & Upper & Lower \\
\hline Other & 49,533 & 50,800 & 44,300 & 50,900 & 6600 & 1812 & 45,982 & 53,085 \\
Marble & 41,473 & 42,231 & $*$ & $*$ & $*$ & 928 & 39,654 & 43,292 \\
Graph & 49,605 & 47,900 & 45,800 & 52,300 & 6500 & 1270 & 47,115 & 52,095 \\
Coal & 49,496 & 51,090 & 45,000 & 56,000 & 11,000 & 2387 & 44,816 & 54,176 \\
Benz & 41,919 & 41,764 & 36,030 & 45,830 & 9800 & 1560 & 38,860 & 44,978 \\
Anth & 51,214 & 53,140 & 50,600 & 54,500 & 3900 & 1639 & 48,000 & 54,428 \\
\hline
\end{tabular}

$\mathrm{a} *$ indicates that there were insufficient data to complete the calculation

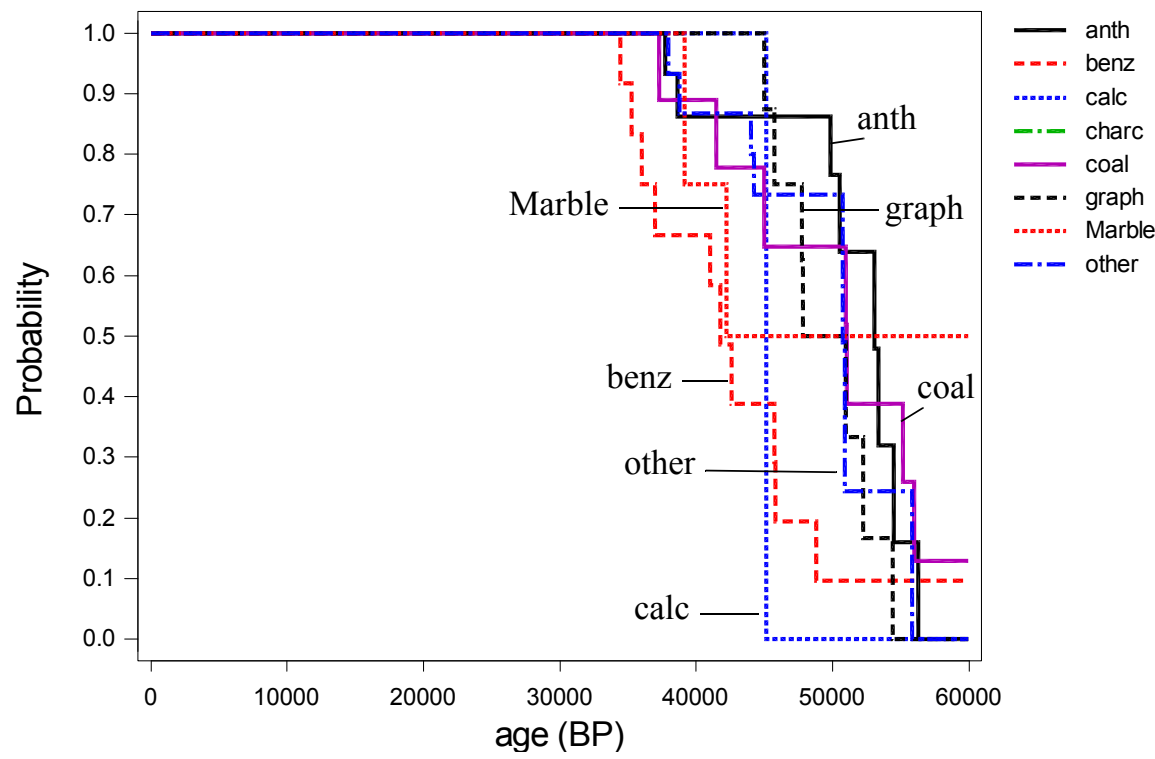

Figure 6.14 Cumulative age distribution by background material (charcoal not shown) 


\subsection{ANALYSIS OF AGE, COMBINED RESULTS}

In total, of the 166 measurements on A and B combined, 57 were censored. The overall results are summarized below (Table 6.21) and show a median age of $48,305 \mathrm{BP}$, and the $50 \%$ range of the data as $43,900-51,800 \mathrm{BP}$.

Table 6.21 Age estimation (A and B combined)

\begin{tabular}{llllllll}
\hline & & & & & & \multicolumn{2}{c}{$95.0 \%$ normal CI } \\
\cline { 7 - 8 } Mean & Median & Q1 & Q3 & IQR & Standard error & Upper & Lower \\
\hline 47,634 & 48,305 & 43,900 & 51,800 & 7900 & 555 & 46,545 & 48,723 \\
\hline
\end{tabular}

\subsubsection{Sources of Variation}

The 3 main sources of variation — laboratory type, modern standard, and background material—are analyzed in the following sections.

\subsubsection{Effect of Laboratory Type}

Again, laboratory type is found to be highly significant. From Table 6.22, the mean and median age reported by AMS laboratories is approximately 2000 and 5000 yr greater than GPC and LSC laboratories, respectively. Figure 6.15 shows the cumulative age distribution curves, with the LSC curve lying below those for AMS and GPC.

Table 6.22 Age by laboratory type

\begin{tabular}{lccccrcrc}
\hline & & & & & & & \multicolumn{2}{c}{$95.0 \%$ normal CI } \\
\cline { 7 - 9 } & Mean & Median & Q1 & \multicolumn{1}{c}{ Q3 } & \multicolumn{1}{c}{ IQR } & Standard error & Upper & Lower \\
\hline AMS & 50,007 & 50,800 & 47,490 & 52,300 & 4810 & 533 & 48,961 & 51,054 \\
GPC & 48,097 & 48,305 & 42,440 & 53,140 & 10,700 & 1090 & 45,960 & 50,234 \\
LSC & 45,039 & 44,300 & 40,190 & 49,580 & 9390 & 1130 & 42,824 & 47,254 \\
\hline
\end{tabular}

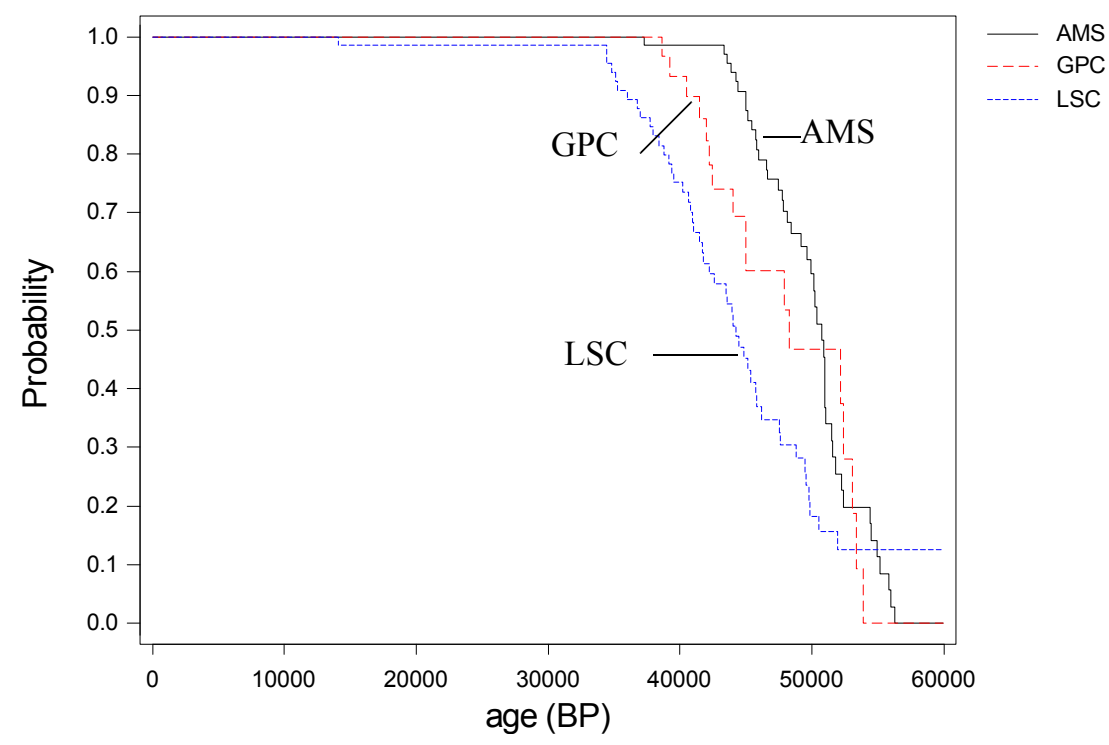

Figure 6.15 Cumulative age distribution by laboratory type

\subsubsection{Effect of Modern Standard}

A statistically significant difference in age distributions due to modern standard is found (Figure 6.16). 


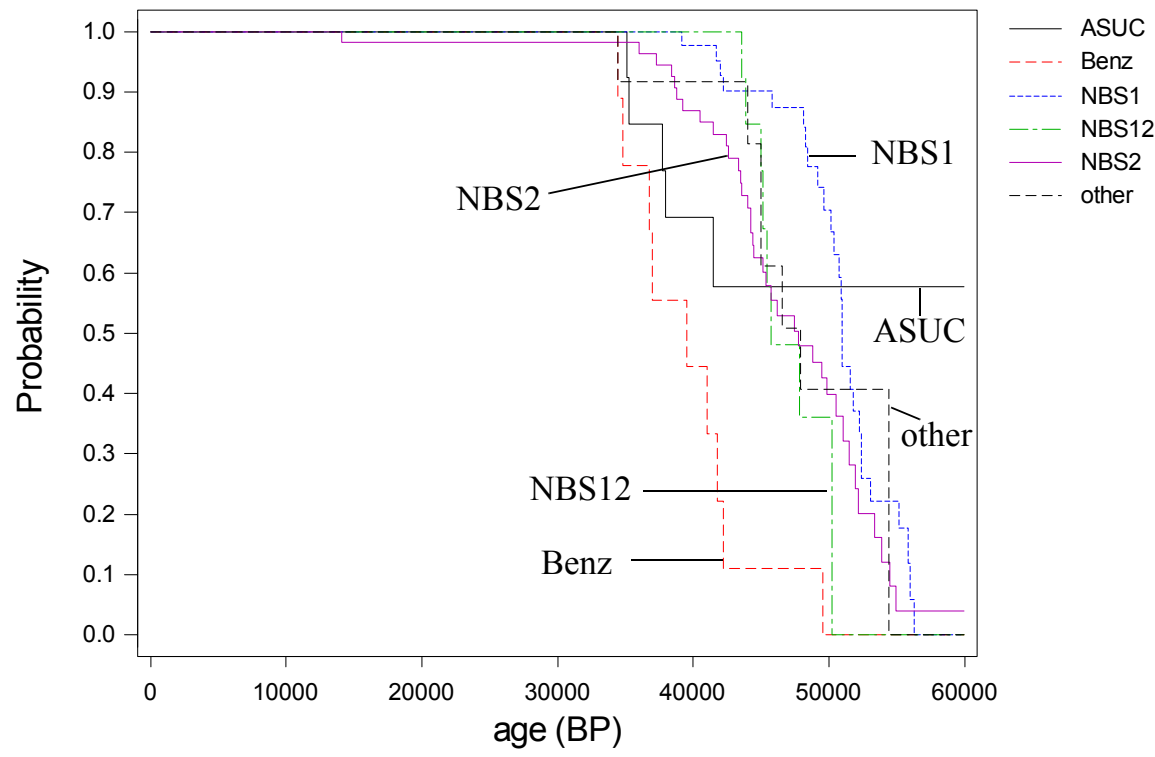

Figure 6.16 Cumulative age distribution by modern standard material

NIST OXI shows an age distribution that favors older ages, while laboratories using benzene as the modern standard quote overall younger ages, suggesting that the benzene activity is too high in comparison to the primary standards of NIST OXI and OXII.

\subsubsection{Effect by Background Material}

A statistically significant difference in the age distributions due to background material is found (Figure 6.17).

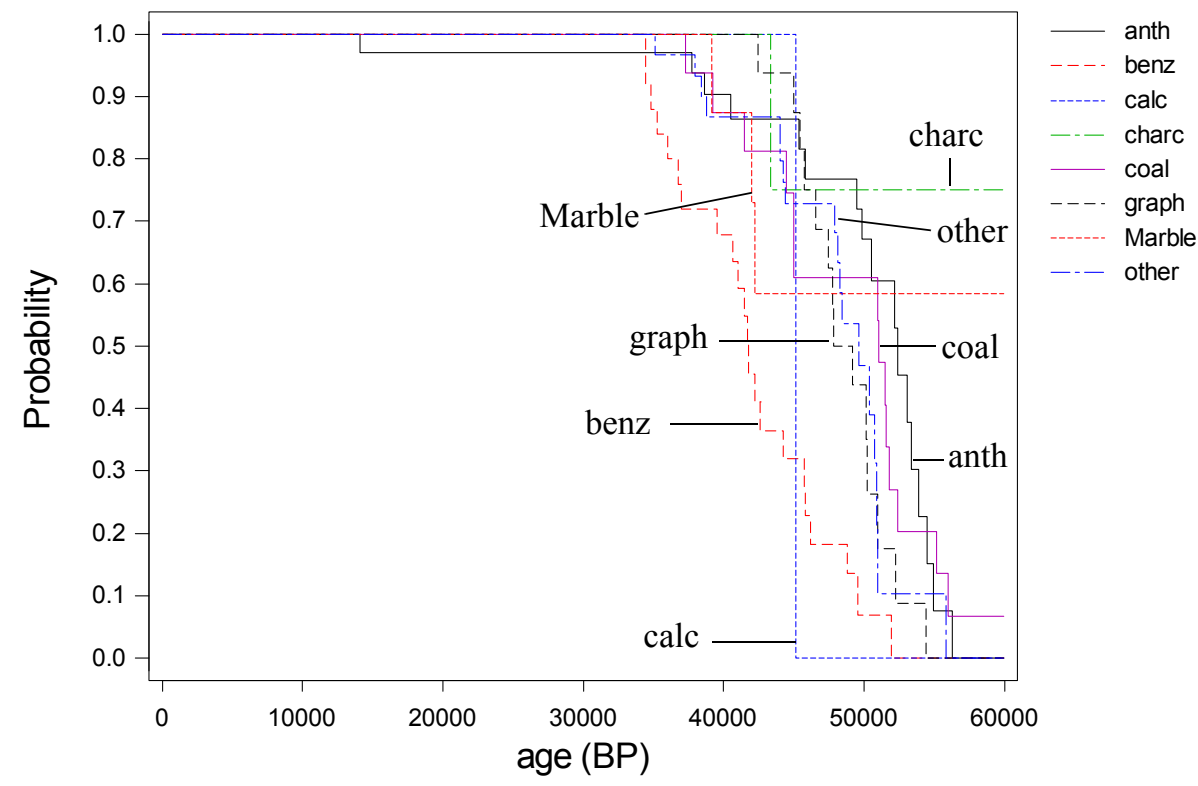

Figure 6.17 Cumulative age distribution by background material 
There is a suggestion that laboratories using benzene as the background material are quoting younger ages on average.

\subsection{CONCLUSIONS}

Overall, this analysis has demonstrated significant differences between the laboratory types in the age distribution quoted for this near-background sample. At the same time, the effects of the modern standard and the background material have also been identified. This most sensitive sample to the laboratory parameters has shown significant differences due to laboratory type (LSC laboratories appear to be significantly different from AMS and GPC laboratories). This finding is further supported by the findings for the effects of modern standard and background material (where the use of benzene has been identified). Further, the intercomparison has also underlined the variation in the calculation and reporting formats for near-background samples. 